\title{
Short Communication Alcohol intake and risk of thyroid cancer in the NIH-AARP Diet and Health Study
}

\author{
CL Meinhold*,', Y Park', RZ Stolzenberg-Solomon', AR Hollenbeck ${ }^{2}$, A Schatzkin' and A Berrington de Gonzalez' \\ 'Division of Cancer Epidemiology and Genetics, National Cancer Institute, National Institutes of Health, Rockville, MD, USA; ${ }^{2}$ AARP, Washington, DC, \\ USA
}

BACKGROUND: Certain studies suggest that alcohol may reduce the risk of thyroid cancer in women, but the effect in men remains unclear.

METHODS: We analysed the association between alcohol and thyroid cancer in a large $(n=490$ I59) prospective NIH-AARP Diet and Health Study with self-reported beer, wine, and liquor intakes.

RESULTS: Over 7.5 years of follow-up (median), 170 men and 200 women developed thyroid cancer. Overall, the thyroid cancer risk decreased with greater alcohol consumption ( $\geqslant 2$ drinks per day vs none, relative risk $=0.57,95 \% \mathrm{Cl} 0.36-0.89, P$-trend $=0.0 \mathrm{l}$ ).

CONCLUSIONS: These results suggest a potential protective role for alcohol consumption in thyroid cancer.

British Journal of Cancer (2009) I I , 1630- 1634. doi: I0.1038/sj.bjc.6605337 www.bjcancer.com

Published online 29 September 2009

(C) 2009 Cancer Research UK

Keywords: thyroid cancer; alcohol drinking; cohort study; epidemiology

The rapid increase in thyroid cancer incidence in the United States over the past three decades may be related to changes in certain environmental exposures, as well as increased surveillance and more widespread use of sensitive diagnostic tools (Enewold et al, 2009). However, despite many retrospective studies, few risk factors have been established other than childhood exposure to ionizing radiation (Dal Maso et al, 2009).

Certain studies have suggested an inverse association between alcohol and thyroid cancer risk, but this may be confounded by cigarette smoking, which is correlated with alcohol consumption and has been inversely related with thyroid cancer (Mack et al, 2003; Jee et al, 2004; Nagano et al, 2007). However, no association was observed in a pooled analysis of 14 case-control studies after adjusting for smoking (Mack et al, 2003), or in two prospective studies with fewer than 200 cases (Iribarren et al, 2001; Navarro Silvera et al, 2005), although these studies were consistent with a small reduction in risk. A larger prospective study in women (421 cases) showed a clear reduction in risk with greater alcohol consumption (Allen et al, 2009). Although it remains unclear whether an association between alcohol and thyroid cancer exists independently of smoking, there is also a need to investigate effect modification by sex, given the three-fold higher incidence of thyroid cancer in women compared with men (Jemal et al, 2008).

*Correspondence: CL Meinhold, Division of Cancer Epidemiology and Genetics, National Cancer Institute, National Institutes of Health, 6120 Executive Boulevard, Rockville, MD 20852, USA;

E-mail: meinholdc@mail.nih.gov

Received 29 July 2009; revised 28 August 2009; accepted 4 September 2009; published online 29 September 2009
Given the evidence of a possible association and a recent decrease in alcohol consumption in the United States (Zhang et al, 2008; Kerr et al, 2009), we analysed the association between alcohol intake and the risk of thyroid cancer and its sub-types in a large US prospective study of over 490000 participants, including more than 292000 men.

\section{MATERIALS AND METHODS}

The NIH-AARP Diet and Health Study began in 1995-1996 when a questionnaire was mailed to AARP members, aged 50-71 years, residing in six US states (California, Florida, Louisiana, New Jersey, North Carolina, and Pennsylvania) and two metropolitan areas (Atlanta and Detroit; Schatzkin et al, 2001). Participant mailings and annual linkage to 11 state cancer registries and the National Death Index provide information on cancer and mortality outcomes. The NIH-AARP Study was approved by the special studies institutional review board of the US National Cancer Institute. Further details on this cohort have been previously described (Schatzkin et al, 2001).

Among 567169 questionnaire respondents, we excluded individuals who provided duplicate questionnaires $(n=179)$, withdrew from the study $(n=6)$, moved outside the study area or died before follow-up $(n=617)$, were proxy respondents $(n=15760)$, had prevalent cancer except non-melanoma skin cancer $(n=51193)$ or end-stage renal disease at baseline $(n=997)$, had cancer identified only from death records $(n=3876)$, or had missing or extreme (greater than twice the interquartile range of sex-specific transformed intake above the 75th or below the 25 th percentile) caloric intake $(n=4382)$. The analytic cohort included 490159 participants (292 101 men and 198058 women). 
We defined incident thyroid cancer cases as first invasive, malignant neoplasm diagnosed during follow-up, and classified histology according to International Classification of Diseases for Oncology, Third Edition codes (C739) (Fritz et al, 2000).

The self-administered baseline questionnaire inquired about health-related behaviours, demographics, and anthropometric characteristics. A supplementary food frequency questionnaire elicited information on regular dietary habits over the past year, including serving sizes and frequency of intake of beer during the summer and rest of the year, wine, and liquor. On the basis of this information, alcohol consumption was standardised according to the MyPyramid Servings database of the US Department of Agriculture. One serving (drink) corresponds to 12 fluid ounces of beer (12.96 g ethanol), 5 fluid ounces of wine (13.72 $\mathrm{g}$ ethanol), and 1.5 fluid ounces of 80 -proof distilled spirits (13.93 g ethanol).

Cox proportional hazards models with attained age as the time metric were used to estimate relative risks (RR) and 95\% confidence intervals (CI) for thyroid cancer in all participants and by sex. Models were additionally adjusted for sex, race, smoking status, body mass index (BMI), and family history of cancer. We mutually adjusted for beer, wine, and liquor in models of alcohol type. Medians of each exposure category were modeled as continuous in trend tests. Sub-group analyses were conducted using categories of sex, smoking status, BMI, and thyroid cancer histology. The heterogeneity within subgroups was assessed using the $Q$ statistic (Cochran, 1954). We found no evidence that the proportional hazards assumption was violated.

\section{RESULTS}

The median alcohol intake among participants reporting any alcohol consumption over the past year was $4.5 \mathrm{~g}$ per day, or approximately one-third of the amount of a standard alcoholic drink. Over $11 \%$ of the cohort ( 9574 women and 45149 men) reported consuming two or more alcoholic drinks daily. There were higher proportions of beer or liquor drinkers among the heavier drinking groups, and of wine drinkers among the more moderate drinking group. Compared with non-drinkers, heavier drinkers were more likely to be male, white non-Hispanic, more educated, and to have ever smoked, and less likely to be obese (Table 1).

Over a median 7.5 years of follow-up, 200 women and 170 men were diagnosed with thyroid cancer. Compared with non-drinking, consuming two or more drinks per day was associated with a significantly decreased risk $(R R=0.57,95 \%$ CI $0.36-0.89, P$ trend $=0.01$; Table 2). Consuming one or more drinks per day of beer was associated with a decreased risk when compared with no beer drinking, particularly in men $(\mathrm{RR}=0.47,95 \% \mathrm{CI} 0.22-0.97$, $P$-trend $=0.03)$. No clear dose-response associations with wine were observed, but liquor intake was associated with a nonsignificant decreased risk in women.

The strength of the inverse association with alcohol intake was relatively consistent according to sex, smoking status, and BMI categories, as well as histology (Figure 1). It was stronger in participants who never smoked $(\mathrm{RR}=0.33,95 \%$ CI $0.16-0.71)$ when compared with ever smokers $(\mathrm{RR}=0.78,95 \%$ CI $0.51-1.19$; $P$-heterogeneity $=0.05)$. Although we observed a clearer inverse association for papillary $(\mathrm{RR}=0.58,95 \% \mathrm{CI} 0.38-0.88)$ as compared with follicular cancer $(R R=0.86,95 \%$ CI $0.41-1.80)$, these results were not significantly different ( $P$-heterogeneity $=0.36)$. For every $10 \mathrm{~g}$ consumed, the RRs for thyroid cancer were 0.95 (95\% CI $0.89-1.01)$ for men, 0.84 (95\% CI 0.71 $1.01)$ for women, and 0.94 (95\% CI 0.88-0.99) for men and women combined. The results were not materially altered after excluding
Table I Study characteristics by alcohol intake (medians or percentage), using the NIH-AARP Diet and Health Study $(n=490$ I59)

\begin{tabular}{|c|c|c|c|c|c|}
\hline & \multicolumn{5}{|c|}{ Alcohol (drinks) } \\
\hline & None & $\begin{array}{c}<\text { I per } \\
\text { week }\end{array}$ & $\begin{array}{l}\text { I-6 per } \\
\text { week }\end{array}$ & $\begin{array}{c}\text { I-2 per } \\
\text { day }\end{array}$ & $\begin{array}{c}2 \text { per } \\
\text { day }\end{array}$ \\
\hline Study participants & 119172 & 131726 & 127340 & 57198 & 54723 \\
\hline Alcohol (drinks per day) & 0 & 0.06 & 0.38 & 1.34 & 3.66 \\
\hline Alcohol (g per day) & 0 & 0.79 & 5.16 & 17.91 & 50.84 \\
\hline \multicolumn{6}{|l|}{ Drinking pattern (\%) } \\
\hline Mostly beer drinkers ${ }^{\dagger}$ & $\mathrm{N} / \mathrm{A}$ & 20 & 27 & 23 & 33 \\
\hline Mostly wine drinkers ${ }^{\dagger}$ & N/A & 42 & 36 & 36 & 18 \\
\hline Mostly liquor drinkers ${ }^{\dagger}$ & $\mathrm{N} / \mathrm{A}$ & 28 & 24 & 36 & 46 \\
\hline Mixed & $\mathrm{N} / \mathrm{A}$ & 10 & 13 & 5 & 4 \\
\hline Age at entry & 63.0 & 62.4 & 62.1 & 63.1 & 62.6 \\
\hline \multicolumn{6}{|l|}{$\operatorname{Sex}(\%)$} \\
\hline Women & 49 & 54 & 34 & 28 & 18 \\
\hline Men & 51 & 46 & 67 & 72 & 83 \\
\hline \multicolumn{6}{|l|}{ Race/ethnicity (\%) } \\
\hline White, non-Hispanic & 87 & 91 & 93 & 95 & 95 \\
\hline Black, non-Hispanic & 6 & 4 & 3 & 2 & 2 \\
\hline Other & 4 & 4 & 3 & 3 & 2 \\
\hline Missing & 2 & 1 & 1 & 1 & 1 \\
\hline \multicolumn{6}{|l|}{ Education (\%) } \\
\hline Less than high school & 35 & 28 & 20 & 18 & 20 \\
\hline High school graduate & 10 & || & 9 & 9 & 9 \\
\hline Some college & 22 & 24 & 24 & 23 & 24 \\
\hline College graduate & 29 & 35 & 44 & 49 & 45 \\
\hline Missing & 4 & 3 & 3 & 2 & 2 \\
\hline \multicolumn{6}{|l|}{ Body mass index (\%) } \\
\hline$<25 \mathrm{~kg} \mathrm{~m}^{-2}$ & 32 & 34 & 36 & 40 & 34 \\
\hline $25-29.9 \mathrm{~kg} \mathrm{~m}^{-2}$ & 39 & 39 & 44 & 44 & 46 \\
\hline$\geqslant 30 \mathrm{~kg} \mathrm{~m}^{-2}$ & 26 & 24 & 18 & 15 & 18 \\
\hline Missing & 3 & 2 & 2 & 2 & 2 \\
\hline \multicolumn{6}{|l|}{ Cigarette smoking status (\%) } \\
\hline Never & 43 & 41 & 33 & 26 & 18 \\
\hline Former & 42 & 44 & 53 & 58 & 60 \\
\hline Current & | | & 12 & 10 & 12 & 19 \\
\hline Missing & 4 & 4 & 4 & 4 & 4 \\
\hline \multicolumn{6}{|l|}{ Family history of cancer (\%) } \\
\hline No & 46 & 46 & 46 & 46 & 47 \\
\hline Yes & 48 & 49 & 49 & 49 & 48 \\
\hline Missing & 6 & 5 & 5 & 5 & 5 \\
\hline
\end{tabular}

Gram intake of specific alcohol type accounts for $750 \%$ of total alcohol intake.

the first 2 years of follow-up, when the lightest drinkers were considered as the referent category, or when models were additionally adjusted for smoking intensity (data not shown).

\section{DISCUSSION}

In this large prospective study, we observed that greater alcohol intake was associated with a reduced risk of thyroid cancer in both men and women, independent of cigarette smoking. The inverse association for beer seemed stronger than for wine or liquor, particularly among men in this cohort. In women, we observed a nonsignificant inverse association for liquor intake, but no clear association for other alcohol types. These differences may reflect the smaller range of alcohol intake in women, residual confounding by socioeconomic status or related factors, drinking patterns (i.e., binge drinking), or differences in measurement error by the 
Table 2 Association between the level of alcohol intake and thyroid cancer risk, using the NIH-AARP Diet and Health Study, ( $n=490$ I59)

\begin{tabular}{|c|c|c|c|c|c|c|c|c|c|}
\hline & \multicolumn{3}{|c|}{ Total $(n=490$ I59) } & \multicolumn{3}{|c|}{ Women $(n=198058)$} & \multicolumn{3}{|c|}{$\operatorname{Men}(n=292101)$} \\
\hline & $\begin{array}{c}\text { Cases/person- } \\
\text { years }\end{array}$ & $\mathbf{R R}^{\mathbf{a}}$ & $\begin{array}{c}\mathbf{R R} \\
(95 \% \mathrm{Cl})^{\mathbf{b}}\end{array}$ & $\begin{array}{c}\text { Cases/person- } \\
\text { years }\end{array}$ & $\mathbf{R R}^{\mathbf{a}}$ & $\begin{array}{c}\text { RR } \\
(95 \% \text { Cl) }\end{array}$ & $\begin{array}{c}\text { Cases/person- } \\
\text { years }\end{array}$ & $\mathbf{R R}^{\mathbf{a}}$ & $\begin{array}{c}\text { RR } \\
(95 \% \text { Cl) }\end{array}$ \\
\hline \multicolumn{10}{|l|}{ Alcohol (drinks) } \\
\hline None & $109 / 812376$ & 1.00 & I.00 (Reference) & $71 / 405668$ & 1.00 & I.00 (Reference) & $38 / 406708$ & 1.00 & I.00 (Reference) \\
\hline < I per week & $109 / 913627$ & 0.88 & $0.87(0.66-1.13)$ & 70/503 876 & 0.80 & $0.81(0.58-1.14)$ & $39 / 409751$ & 1.02 & $0.97(0.62-1.51)$ \\
\hline I-6 per week & $96 / 878488$ & 0.89 & $0.87(0.66-1.16)$ & $43 / 300016$ & 0.83 & $0.84(0.57-1.24)$ & $53 / 578473$ & 0.99 & $0.90(0.59-1.38)$ \\
\hline P-trend & & & 0.01 & & & 0.06 & & & \\
\hline \multicolumn{10}{|l|}{ Beer (drinks) ${ }^{\mathrm{d}, \mathrm{e}}$} \\
\hline None & $195 / 1542426$ & 1.00 & I.00 (Reference) & 135/896073 & 1.00 & I.00 (Reference) & $60 / 646353$ & 1.00 & 1.00 (Reference) \\
\hline$<$ I per week & $128 / \mid$ | | 220 & 1.02 & $1.02(0.79-1.32)$ & $56 / 398773$ & 1.01 & $1.02(0.72-1.44)$ & $72 / 7 \mid 2447$ & 0.99 & $0.99(0.66-1.48)$ \\
\hline I-6 per week & $38 / 48 \mid 530$ & 0.79 & $0.79(0.53-1.17)$ & $9 / 91697$ & $0.72^{f}$ & $0.75(0.37-1.49)^{f}$ & $29 / 408543$ & 0.71 & $0.72(0.44-1.21)$ \\
\hline$\geqslant 1$ per day & $9 / 232293$ & 0.40 & $0.42(0.21-0.83)$ & - & - & - & $9 / 213583$ & 0.43 & $0.47(0.22-0.97)$ \\
\hline \multicolumn{10}{|l|}{ Wine (drinks) ${ }^{\text {e,g }}$} \\
\hline I-6 per week & $61 / 556399$ & 1.11 & $1.09(0.77-1.54)$ & $30 / 204015$ & 1.16 & $1.15(0.7 \mid-1.86)$ & $31 / 352384$ & 1.08 & $1.00(0.61-1.63)$ \\
\hline$\geqslant 1$ per day & $17 / 225863$ & 0.77 & $0.76(0.45-1.29)$ & $8 / 76870$ & 0.81 & $0.83(0.39-1.77)$ & $9 / 148993$ & 0.73 & $0.69(0.33-1.43)$ \\
\hline P-trend & & & 0.69 & & & 0.62 & & & 0.33 \\
\hline \multicolumn{10}{|l|}{ Liquor (drinks) ${ }^{e, h}$} \\
\hline None & |87/I 575603 & 1.00 & I.00 (Reference) & $117 / 725512$ & 1.00 & ।.00 (Reference) & 70/850 091 & 1.00 & 1.00 (Reference) \\
\hline <। per week & |24/| | 45879 & 0.93 & $0.93(0.71-1.20)$ & 63/493054 & 0.78 & $0.79(0.56-1.11)$ & $61 / 652825$ & 1.20 & $1.15(0.77-1.72)$ \\
\hline I-6 per week & 27/332326 & 0.79 & $0.79(0.51-1.22)$ & $12 / 92127$ & 0.79 & $0.82(0.44-1.54)$ & |5/240 |99 & 0.87 & $0.81(0.44-1.50)$ \\
\hline$\geqslant 1$ per day & $32 / 313660$ & 1.02 & $1.02(0.68-1.53)$ & $8 / 75849$ & 0.65 & $0.70(0.33-1.47)$ & $24 / 237811$ & 1.40 & $1.25(0.74-2.11)$ \\
\hline P-trend & & & 0.80 & & & 0.46 & & & 0.52 \\
\hline
\end{tabular}

${ }^{a}$ Adjusted for age and sex. ${ }^{b}$ Adjusted for age, sex, race (non-Hispanic white, non-Hispanic black, other, or missing), education (less than high school, high school graduate, some college, college graduate, or missing), smoking status (never, former, current, or missing), body mass index (BMI $<25,25-29.9, \geqslant 30 \mathrm{~kg} \mathrm{~m}{ }^{-2}$, or missing), and family history of cancer (no, yes, or missing). 'Relative risks for $\geqslant 1$ drink per day vs none. ${ }^{\mathrm{d}}$ One standardized drink of beer is equal to $12.96 \mathrm{~g}$ of alcohol. ${ }^{e}$ Beer, wine, and liquor were mutually adjusted for in age- and sex-adjusted and multivariable-adjusted models. ${ }^{\mathrm{f}}$ Relative risks for $\geqslant 1$ drinks per week vs none. ${ }^{\mathrm{g}} \mathrm{O}$.

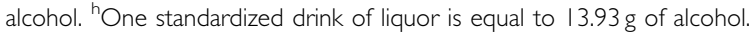

type of alcohol. Nonetheless, similar dose-response associations with total alcohol intake were observed by sex, and associations by alcohol type were generally in the same inverse direction. Although we observed a clearer reduction in risk for papillary $v s$ follicular cancers, this difference was not significant. However, there were only 64 follicular cancers in this study.

Given the strong, positive correlation between alcohol and smoking, and the evidence linking smoking with a reduced risk of thyroid cancer (Mack et al, 2003; Jee et al, 2004; Nagano et al, 2007), residual confounding by smoking may have biased our results away from the null. However, this seems unlikely as a stronger inverse association for alcohol was observed for never when compared with ever cigarette smokers.

In a cross-sectional study using ultrasonography, an inverse association between alcohol consumption and thyroid enlargement and nodularity was observed (Knudsen et al, 2001). A positive association between alcohol consumption and thyroid-stimulating hormone (TSH) and an inverse association with serum T3 was also found. Thyroid-stimulating hormone, which is secreted by the pituitary in response to low thyroid hormone levels in the blood, is known to increase the proliferation of follicular thyroid cells in laboratory studies (Williams, 1990), although its effect in humans is not clearly established. Alcohol may protect the thyroid from elevated TSH by inhibiting thyroid hormone metabolism (Knudsen et al, 2001). Greater alcohol intake may lead to vitamin deficiencies, impaired folate metabolism, oxidative stress, and
DNA damage (Boffetta and Hashibe, 2006); but whether these directly influence the thyroid is unknown.

This is one of the few prospective studies to examine the relation between alcohol and thyroid cancer risk. A reasonably large number of cases allowed for sub-group analyses by sex, BMI, smoking status, and thyroid cancer sub-types; however, there were too few cases to obtain stable RRs in the heavier-drinking categories $(\geqslant 2$ drinks per day). Participants reported intake during the past year, which obviously does not cover cumulative lifetime drinking, and our results could be attenuated by the inclusion of recent quitters in the reference category of nondrinkers. However, excluding the first 2 years of follow-up did not materially change the results, and a similar inverse dose-response association was observed when the lightest drinkers were the referent group.

In this large prospective study, we found a reduction in thyroid cancer risk in both men and women with a greater consumption of alcohol. The decrease in risk associated with consuming $10 \mathrm{~g}$ per day is reasonably consistent between women in this study and in another large prospective study ( 16 vs $25 \%$ per $10 \mathrm{~g}$ per day; Allen et al, 2009). However, the direct public health applications of these findings are limited, considering the evidence linking moderate-to-heavy alcohol consumption with increases in several cancers, among other adverse effects (Boffetta and Hashibe, 2006). Nonetheless, as thyroid cancer incidence is rising, it is important to analyse the influence of diet and lifestyle in its aetiology. 
Relative risk $(95 \% \mathrm{Cl})$

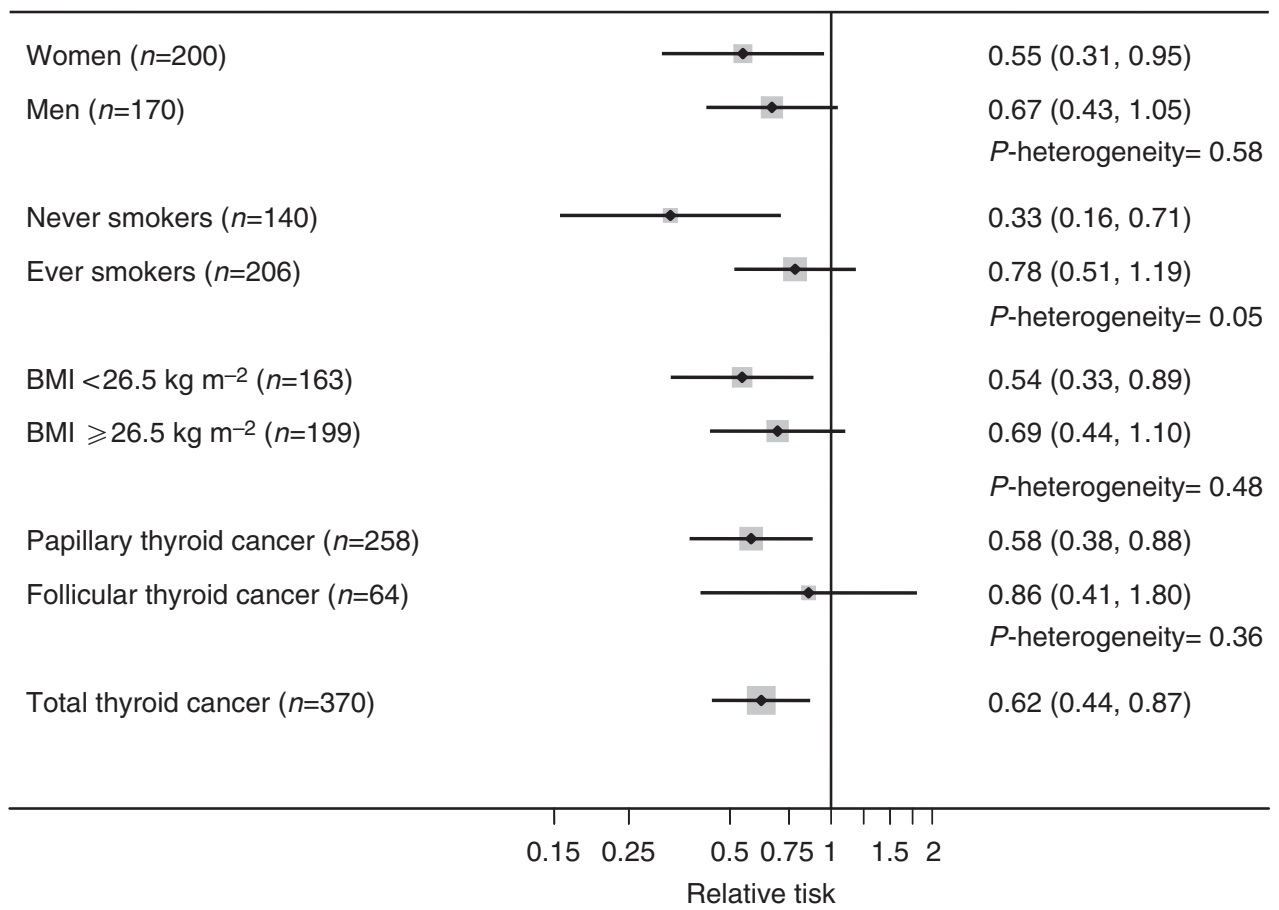

Figure I Associations between alcohol intake ( $\geqslant$ I drink per day vs none) and thyroid cancer risk by sex, smoking status, body mass index (BMI), and histological type, using the NIH-AARP Diet and Health Study $(n=490$ I59). The models were adjusted for age, sex, race (non-Hispanic white, non-Hispanic black, other, or missing), education (less than high school, high school graduate, some college, college graduate, or missing), smoking status (never, former, current, or missing), body mass index (BMl $<25.25-29.9, \geqslant 30 \mathrm{~kg} \mathrm{~m}^{-2}$ or missing), and family history of cancer (no, yes, or missing).

\section{ACKNOWLEDGEMENTS}

This research was supported, in part, by the Intramural Research Program of the National Institutes of Health, National Cancer Institute. Cancer incidence data from the Atlanta metropolitan area were collected by the Georgia Center for Cancer Statistics, Department of Epidemiology, Rollins School of Public Health, Emory University. Cancer incidence data from California were collected by the California Department of Health Services, Cancer Surveillance Section. Cancer incidence data from the Detroit metropolitan area were collected by the Michigan Cancer Surveillance Program, Community Health Administration, State of Michigan. The Florida cancer incidence data used in this report were collected by the Florida Cancer Data System under contract to the Department of Health (DOH). The views expressed in this study are solely those of the authors and do not necessarily reflect those of the contractor or $\mathrm{DOH}$. Cancer incidence data from Louisiana were collected by the Louisiana Tumor Registry, Louisiana State University Medical Center in New Orleans. Cancer incidence data from New Jersey were collected by the New Jersey State Cancer Registry, Cancer Epidemiology Services, New Jersey State Department of Health and Senior Services. Cancer incidence

\section{REFERENCES}

Allen NE, Beral V, Casabonne D, Kan SW, Reeves GK, Brown A, Green J, Million Women Study Collaborators (2009) Moderate alcohol intake and cancer incidence in women. J Natl Cancer Inst 101: 296-305

Boffetta P, Hashibe M (2006) Alcohol and cancer. Lancet Oncol 7: 149-156 Cochran WG (1954) The combination of estimates from different experiments. Biometrics 10: $101-129$ data from North Carolina were collected by the North Carolina Central Cancer Registry. Cancer incidence data from Pennsylvania were supplied by the Division of Health Statistics and Research, Pennsylvania Department of Health, Harrisburg, Pennsylvania. The Pennsylvania Department of Health specifically disclaims responsibility for any analyses, interpretations, or conclusions. Cancer incidence data from Arizona were collected by the Arizona Cancer Registry, Division of Public Health Services, Arizona Department of Health Services. Cancer incidence data from Texas were collected by the Texas Cancer Registry, Cancer Epidemiology and Surveillance Branch, Texas Department of State Health Services. Cancer incidence data from Nevada were collected by the Nevada Central Cancer Registry, Center for Health Data and Research, Bureau of Health Planning and Statistics, State Health Division, State of Nevada Department of Health and Human Services.

We are indebted to the participants in the NIH-AARP Diet and Health Study for their outstanding cooperation. We also thank Sigurd Hermansen and Kerry Grace Morrissey from Westat for study outcome ascertainment and management and Leslie Carroll at the Information Management Services for data support and analysis.
Dal Maso L, Bosetti C, La Vecchia C, Franceschi S (2009) Risk factors for thyroid cancer: an epidemiological review focused on nutritional factors. Cancer Causes Control 20: 75-86

Enewold L, Zhu K, Ron E, Marrogi AJ, Stojadinovic A, Peoples GE, Devesa SS (2009) Rising thyroid cancer incidence in the United States by demographic and tumor characteristics, 1980-2005. Cancer Epidemiol Biomarkers Prev 18: 784-791 
Fritz A, Percy C, Jack A, Shanmugaratnam K, Sobin L, Parkin DM, Whelan $\mathrm{S}$ (eds) (2000) International Classification of Diseases for Oncology, 3rd edn World Health Organization: Geneva

Iribarren C, Haselkorn T, Tekawa IS, Friedman GD (2001) Cohort study of thyroid cancer in a San Francisco Bay area population. Int J Cancer 93: $745-750$

Jee SH, Samet JM, Ohrr H, Kim JH, Kim IS (2004) Smoking and cancer risk in Korean men and women. Cancer Causes Control 15: $341-348$

Jemal A, Thun MJ, Ries LA, Howe HL, Weir HK, Center MM, Ward E, Wu XC, Eheman C, Anderson R, Ajani UA, Kohler B, Edwards BK (2008) Annual report to the nation on the status of cancer, 1975-2005, featuring trends in lung cancer, tobacco use, and tobacco control. J Natl Cancer Inst 100: $1672-1694$

Kerr WC, Greenfield TK, Bond J, Ye Y, Rehm J (2009) Age-period-cohort modeling of alcohol volume and heavy drinking days in the US National Alcohol Surveys: divergence in younger and older adult trends. Addiction 104: $27-37$

Knudsen N, Bülow I, Laurberg P, Perrild H, Ovesen L, Jørgensen T (2001) Alcohol consumption is associated with reduced prevalence of goiter and solitary thyroid nodules. Clin Endocrinol (Oxf) 55: 41-46

Mack WJ, Preston-Martin S, Dal Maso L, Galanti R, Xiang M, Franceschi S, Hallquist A, Jin F, Kolonel L, LaVecchia C, Levi F, Linos A, Lund E,
McTiernan A, Mabuchi K, Negri E, Wingren G, Ron E (2003) A pooled analysis of case-control studies of thyroid cancer: cigarette smoking and consumption of alcohol, coffee, and tea. Cancer Causes Control 14: $773-785$

Nagano J, Mabuchi K, Yoshimoto Y, Hayashi Y, Tsuda N, Land C, Kodama K (2007) A case-control study in Hiroshima and Nagasaki examining non-radiation risk factors for thyroid cancer. J Epidemiol 17: $76-85$

Navarro Silvera SA, Miller AB, Rohan TE (2005) Risk factors for thyroid cancer: a prospective cohort study. Int J Cancer 116: $433-438$

Schatzkin A, Subar AF, Thompson FE, Harlan LC, Tangrea J, Hollenbeck AR, Hurwitz PE, Coyle L, Schussler N, Michaud DS, Freedman LS, Brown CC, Midthune D, Kipnis V (2001) Design and serendipity in establishing a large cohort with wide dietary intake distributions: the National Institutes of Health-American Association of Retired Persons Diet and Health Study. Am J Epidemiol 154: 1119-1125

Williams ED (1990) TSH and thyroid cancer. Horm Metab Res Suppl 23: $72-75$

Zhang Y, Guo X, Saitz R, Levy D, Sartini E, Niu J, Ellison RC (2008) Secular trends in alcohol consumption over 50 years: the Framingham Study. Am J Med 121: 695-701 